\title{
Lise Öğrencilerinin Edebiyata İlişkin Metaforları
}

\author{
Ayşe Derya ESKIMEN ${ }^{1}$ \\ ${ }^{I}$ Türkçe ve Sosyal Bilimler Eğitimi Bölümü, Eğitim Fakültesi, Kütahya Dumlupınar Üniversitesi, Kütahya, Türkiye
}

Sorumlu Yazar: Ayşe Derya ESKIMEN, deryaeskimen@hotmail.com

Makale Türü: Araştırma Makalesi

Bilgilendirme: Bu makale, 30 Ekim-01 Kasım 2018 tarihleri arasında Çanakkale'de düzenlenmiş olan 2. Uluslararası Sosyal Bilimler Eğitimi Sempozyumunda sözlü bildiri olarak sunulmuştur.

Kaynak Gösterimi: Eskimen, A. D. (2019). Lise öğrencilerinin edebiyata ilişkin metaforları. Eğitimde Kuram ve Uygulama, 15(Özel Say1 1), 1-10. doi: 10.17244/eku.492724

\section{High School Students’ Metaphors About Literature}

\section{Ayşe Derya ESKİMEN ${ }^{1}$}

${ }^{I}$ Department of Turkish and Social Sciences Education, Faculty of Education, Kütahya Dumlupınar University, Kütahya, Turkey

Corresponding Author: Ayşe Derya ESKIMEN, deryaeskimen@ hotmail.com

Article Type: Research Article

Acknowledgement: This article was orally presented as a paper at the 2nd International Symposium on Social Sciences Education organized between 30th October and 1st November in Çanakkale, Turkey.

To Cite This Article: Eskimen, A. D. (2019). Lise öğrencilerinin edebiyata ilişkin metaforları. Eğitimde Kuram ve Uygulama, 15(Special Issue 1), 1-10. doi: 10.17244/eku.492724 
2019, 15(Özel Sayı 1), 1-10

\title{
Lise Öğrencilerinin Edebiyata İlişkin Metaforları
}

\author{
Ayşe Derya ESKİMEN ${ }^{1}$ \\ ${ }^{I}$ Türkçe ve Sosyal Bilimler Eğitimi Bölümü, Ĕ̆itim Fakültesi, Kütahya Dumlupınar Üniversitesi, Kütahya, Türkiye \\ ORCID: https://orcid.org/0000-0002-9155-9971
}

\begin{tabular}{|c|c|}
\hline$\ddot{\mathbf{O} z}$ & Makale Bilgisi \\
\hline $\mathrm{Bu}$ araştırma, lise öğrencilerinin edebiyata yönelik algılarını, metaforlar yardımıyla ortaya & \\
\hline $\begin{array}{l}\text { koymayı amaçlamaktadır. Metafor ve eğitim kavramları birbirleriyle ilişkilidir. Zira } \\
\text { metafor ve metaforik düşünce, öğrencilerin dünyayı anlamlandırma biçimlerini gösterme, } \\
\text { onların edebiyat gibi soyut bir kavrama yönelik düşüncelerini ve tutumlarını } \\
\text { belirleyebilme yönleriyle önemlidir. Buna yönelik olarak çalışmada, öğrencilerden }\end{array}$ & $\begin{array}{l}\text { Anahtar Kelimeler: Eğitim, } \\
\text { Metafor, Edebiyat, Lise } \\
\text { öğrencileri. }\end{array}$ \\
\hline edebiyata ilişkin metafor üretmeleri ve "Edebiyat ........ gibidir/benzer, çünkü; ........." & Makale Geçmişi: \\
\hline şeklinde oluşturulmuş cümleyi doldurmaları istenmiştir. Araştırmanın katılımcılarını, & Geliş: 05 Aralık 2018 \\
\hline Kütahya'da bir devlet okulunda eğitimlerine devam eden lise 9-12. sinıf öğrencileri & Düzeltme: 15 Aralık 2018 \\
\hline oluşturmaktadır. Araştırmada olgu bilim deseni kullanılmıştır. Verilerin çözümlenmesinde & Kabul: 11 Mart 2019 \\
\hline içerik analizi tekniğine yer verilmiş; metaforların çözümlenmesi sürecinde eleme ve & \\
\hline seçme, adlandırma, kategori oluşturma/geliştirme, geçerlik ve güvenirliği sağlama & Makale Türü: Araştırma \\
\hline $\begin{array}{l}\text { aşamaları takip edilmiştir. Çalışmadan elde edilen bulgulardan hareketle, } 187 \text { lise } \\
\text { öğrencisinin } 75 \text { metafor ürettiği görülmüstür. Öğrencilerin en fazla metafor ürettikleri }\end{array}$ & Makalesi \\
\hline kategorilerin 2. ve 5. kategoriler olduğu tespit edilmiştir. Öğrencilerin genel olarak & \\
\hline $\begin{array}{l}\text { edebiyat hakkında olumlu metafor geliştirmiş olmaları da elde edilen diğer bir başka } \\
\text { bulgudur. }\end{array}$ & \\
\hline
\end{tabular}




\begin{tabular}{|c|c|}
\hline Abstract & Article Info \\
\hline $\begin{array}{l}\text { This research aims to reveal perceptions of high school students regarding literature with } \\
\text { the help of metaphors. Accordingly the perceptions of students regarding literature } \\
\text { concepts and this lesson were determined according to class level and gender. Metaphor } \\
\text { and education concepts are related to each other. Yet metaphor and metaphorical ideation } \\
\text { is important for students to show the ways in which they sense the world and to determine } \\
\text { their thoughts and attitudes towards an abstract understanding such as literature. With this } \\
\text { intention, in this study the students were asked to make metaphors regarding literature and } \\
\text { were asked to fill the questionnaire formed as "Literature is like/similar to ......., } \\
\text { because; ........". High school students in 9th-12th grade educated in a state school in } \\
\text { Kütahya form the participants of research. Among qualitative research designs } \\
\text { "Phenomenology" was used in the research. In analysis of data, content analysis method } \\
\text { was included and in analysis period of metaphors elimination and selection, naming, } \\
\text { categorizing, validity and reliability, frequency stages were followed. Based on findings } \\
\text { obtained from research, it was found out that students can form valid metaphors regarding } \\
\text { literature, these metaphors are highly positive and in this sense students are aware of the } \\
\text { importance of literature. Based on the findings obtained from the study, it was observed } \\
\text { that } 187 \text { high school students produced } 75 \text { metaphors. It has been determined that the } \\
\text { categories that students produce most metaphors are the second and fifth categories. }\end{array}$ & $\begin{array}{l}\text { Keywords: Education, } \\
\text { Metaphore, Literature, High } \\
\text { school students. } \\
\text { Article History: } \\
\text { Received: } 05 \text { December } 2018 \\
\text { Revised: } 15 \text { December } 2018 \\
\text { Accepted: } 11 \text { March } 2019 \\
\text { Article Type: Research Article }\end{array}$ \\
\hline
\end{tabular}




\section{Giriş}

Bireylerin birtakım soyut ve karmaşık kavramları, olayları ya da durumları anlamaya ve anlatmaya yönelik başvurdukları "metafor" kavramının tanımları çeşitlidir. Morgan'a (1998) göre bir düşünme ve görme biçimi olan metafor, Lakoff ve Johnson (1980) tarafından bir kavramın belirli yönlerden benzerlik gösteren başka ifadelerle açıklanma biçimi olarak tanımlanmıştır. Edebiyat alanına ilişkin, mecaz, istiare, benzetme, eğretileme (Şemsettin Sami, 1905; Aydın, 2006); anlam dünyamızın resmedilmesi (Pilav ve Uslu Üstten, 2013, s. 1083) olarak da ifade edilen metaforların eğitimle yakın ilişkisi vardır. Hasırcı'nın (2017) da ifade ettiği gibi soyut kavramları açıklamadaki gücü ile metaforların eğitim bilimleri alanında ayrı bir yeri bulunmaktadır. Metaforlar, öğrenmede oldukça kullanışlı bir mekanizma, zihinsel bir yapılandırma, düşüncenin anlamlandırılması yöntemidir. Özellikle konumuzu kapsayan edebiyat gibi soyut bir kavrama öğrencilerin hangi çerçeveden baktıklarını, düşünce yapılarını görebilmek hem bu derse hem de bu kavrama yönelik tutumlarını bilmek önemlidir. Buna yönelik olarak Pilav ve Üstten'in (2013) de belirttiği gibi metafor ve metaforik düşünce öğrencilerin dünyayı görme biçimini aktarması, kişilerin hayat görüşlerinin belirlenmesi, dünyayı anlamlandırmalarında, olay, durum, olgu, kavram ve nesnelerle kurdukları iletişimde büyük önem taşır. $\mathrm{Bu}$ anlamda metaforik düşünme yöntemi, bir öğrenme tarzı olarak da önem arz etmektedir.

Metaforların eğitim-öğretimde kullanımına yönelik tüm bu tanım ve katkılarından hareketle denilebilirki, çalışmamız, edebiyat gibi soyut bir alana ilişkin öğrencilerin düşüncelerini, düşüncelerini aktarırken kullandıkları benzetmeleri, benzetme yönlerini, edebiyata dair tutumlarını saptaması nedeniyle önemli görülmektedir.

$\mathrm{Bu}$ araştırmanın amacı, lise öğrencilerinin soyut ve geniş bir kavram olan edebiyata ilişkin algılarının belirlenmesi, edebiyat kavramıyla ilişkilendirilen metaforların incelenerek ele alınmasıdır. Buna yönelik olarak çalışmada, öğrencilerin üretmiş oldukları metaforların ortak özelliklerinden hareketle çeşitli sınıflandırma ve yorumlamalar yapılmıştır.

\section{Yöntem}

Araştırmada öğrencilerin "edebiyat" kavramına ilişkin algılarını araştırmak amaçlandığı için olgu bilim (fenomenoloji) deseni kullanılmıştır. "Olgubilim deseni, derinlemesine ve ayrıntılı bir anlayışa sahip olmadığımız olgulara odaklanmaktadır. Farkında olduğumuz bu olgular olay, kavramlar, durum ve algı gibi çeşitli şekillerde karşımıza çıkabilmektedir” (Yıldırım \& Şimşek, 2005).

\section{Çalışma Grubu}

Çalışmanın katılımcılarını, 2017-2018 eğitim-öğretim yılında Kütahya il merkezinde bir devlet okulunda eğitimlerine devam eden lise 9-12. sınıf öğrencileri oluşturmaktadır. Çalışma grubunda yer alan öğrencilerin cinsiyete göre frekans ve yüzde dağılımları Tablo 1'de gösterilmiştir.

Tablo 1. Çalışma grubunu oluşturan öğrencilerin cinsiyete göre frekans ve yüzde dağılımları

\begin{tabular}{lll}
\hline Cinsiyet & Frekans & Yüzdelik \\
\hline Kiz & 99 & $\% 53$ \\
Erkek & 88 & $\% 47$ \\
\hline Toplam & 187 & $\% 100$
\end{tabular}

Yukarıda yer alan tabloda da görüldüğü gibi araştırmaya katılan toplam 187 öğrencinin 99’u kız, 88’i erkektir.

\section{Verilerin Toplanması, Çözümlenmesi ve Analizi}

Çalışmada, öğrencilerden edebiyata ilişkin çeşitli metaforlar üretmeleri istenmiştir. Buna yönelik olarak "Edebiyat gibidir/benzer, çünkü; ........" şeklinde oluşturulmuş cümleyi doldurmaları gerektiği belirtilmiştir. Araştırmada verilerin çözümlenmesinde ve değerlendirilmesinde içerik analizi tekniği kullanılmıştır. "İçerik çözümlemesinde temel amaç, toplanan verileri anlamlandırabilecek kavramlara ve ilişkilere ulaşmaktır" (Yıldırım \& Şimşek, 2005, s. 227). Öncelikle, öğrencilere ait metafor cümlelerinin yer aldığ1 veriler değerlendirilmiştir. Sonrasında, öğrencilerin belirlediği metaforlardan geçerli olanlar tespit edilmiş, geçersiz metaforlar çalışma dışında bırakılmıştır. Öğrencilerin üretmiş oldukları metaforlara yönelik verilerin analizi ve yorumlanması dört kategoride gerçekleştirilmiştir. Bunlar, 1. Eleme ve seçme/ayıklama aşaması, 2. Adlandırma aşaması, 3. Kategori oluşturma/geliştirme aşaması, 4. Geçerlik ve güvenirliği sağlama aşamasıdır. Bu süreçte ilgili çalışmalardan (Candan \& Öztaş, 2017; Keray Dinçel \& Yılmaz, 2018; Kaygana, Güney, \& Yapıc1, 2013; Pilav \& Uslu Üstten, 2013; Sevim, 
Veyis, \& Kınay, 2012; Yazıcı, 2012) faydalanılmışıı. Bulguların yorumlanmasında doğrudan alıntılara yer verilmiş; katılımcılardan yapılan doğrudan alıntılarda öğrencinin numarasını ifade eden kodlamalar kullanılmıştır. Örnek olarak, 1 numaralı öğrenci (Ö1) biçiminde verilmiştir.

\section{Eleme ve seçme/ayıklama aşaması}

Öğrenciler tarafindan üretilen metaforların mantıklı bir gerekçe ile ilişkilendirilip ilişkilendirilmediği dikkate alınmıştır. Dolayısıyla cümlelerin bir metafor içerip içermediğine, bir benzetmede bulunup bulunulmadığına ya da birden fazla metafor içermesi gibi durumlara bakılarak uygun olmayan kâğıtlar elenmiştir. Buna bağlı olarak öğrencilerin belirlediği metaforlardan geçerli olanlar tespit edilmiş, on adet geçersiz metafor çalışma dışında bırakılmıştır.

\section{Adlandırma aşaması:}

Öğrencilerin ürettiği metaforlar isimler verilerek listelenmiştir.

\section{Kategori oluşturma/geliştirme aşaması:}

Metaforlar sahip oldukları ortak özelliklerden hareketle kavramsal sınıflandırmalar altında bir araya getirilmiştir. Buna yönelik olarak beş sınıflandırma gerçekleştirilmiştir. Örneğin; "Araç, Eşya, Çeşitlilik/Farklılık, Somut Olarak Edebiyat" kategorisinde yer alan metaforların öne çıkan özelliği ögrencilerin edebiyatı çok çeşitli ve farklı somut eşyalar gibi görmüş olmalarıdır (Örneğin: "Edebiyat mum gibidir, çünkü; etrafına 1şık saçar"; "Edebiyat telefon gibidir, çünkü; o olmazsa hayat durur").

\section{Geçerlilik ve güvenirliği sağlama aşaması:}

Çalı̧̧mada, metaforların ortak özelliklerinden hareketle oluşturulan kategorilerin ve bu kategorilerin altında yer verilen metaforların doğruluğuna yönelik iki uzmanın görüşüne başvurulmuştur. Bu görüşler doğrultusunda çeşitli düzeltmeler ve düzenlemeler gerçekleştirilmiştir.

\section{Bulgular ve Yorum}

Araştırmaya katılan öğrencilerin edebiyat kavramına yönelik ürettikleri geçerli metaforlar tablolaştırılmış; veriler, kategori oluşturma/geliştirme aşamasından sonra yorumlanmıştır.

Tablo 2. Lise öğrencilerinin edebiyat kavramına yönelik geliştirdikleri geçerli metaforlar ve öğrenci sayısı (f)

\begin{tabular}{|c|c|c|c|c|c|c|c|c|}
\hline No & Metaforun Adı & Frekans & No & Metaforun Adı & Frekans & No & Metaforun Adı & Frekans \\
\hline 1 & Ağaç & 8 & 27 & Felsefe & 2 & 53 & Müzik & 1 \\
\hline 2 & Aç1 & 1 & 28 & Futbol & 3 & 54 & Nefes & 1 \\
\hline 3 & Anlaşılmak/Anlamak & 1 & 29 & Geometri & 1 & 55 & Orman & 3 \\
\hline 4 & Arkadaş/Dost/Sırdaş & 4 & 30 & Gökkuşağ1 & 4 & 56 & Özgürlük & 1 \\
\hline 5 & Așk & 9 & 31 & Gökyüzü & 2 & 57 & Oksijen & 1 \\
\hline 6 & Aşure & 1 & 32 & Güneş & 4 & 58 & Rüya & 2 \\
\hline 7 & Ay & 1 & 33 & Güneş Gözlüğü & 1 & 59 & Sanat & 4 \\
\hline 8 & Ayna & 3 & 34 & Hayat & 23 & 60 & Sarmaşık & 1 \\
\hline 9 & Balık & 1 & 35 & Hayal & 3 & 61 & Sevgili & 5 \\
\hline 10 & Bayrak & 1 & 36 & Iş̧1k & 2 & 62 & $\mathrm{Su}$ & 9 \\
\hline 11 & Biçim/Hamur & 3 & 37 & Issiz Bir Ada & 1 & 63 & Süslü Söz & 1 \\
\hline 12 & Bozuk Bir Yoğurt & 1 & 38 & İp Yumağ1 & 1 & 64 & Şarap & 4 \\
\hline 13 & Bulmaca & 1 & 39 & İlaç & 3 & 65 & Şemsiye & 1 \\
\hline 14 & Çamur & 1 & 40 & İnsan & 6 & 66 & Şiir & 1 \\
\hline 15 & Çaresizlik & 1 & 41 & Kadın & 6 & 67 & Tarih & 3 \\
\hline 16 & Çiçek:/Gül & 4 & 42 & Kalem & 2 & 68 & Tarih Kitab1 & 1 \\
\hline 17 & Çocuk & 1 & 43 & Kapalı Kutu & 1 & 69 & Telefon & 3 \\
\hline 18 & Çikolata & 1 & 44 & Kayık & 1 & 70 & Tiyatro/Film & 2 \\
\hline 19 & Çöp & 1 & 45 & Kılıç & 1 & 71 & Tohum/Filiz & 3 \\
\hline 20 & Dil & 4 & 46 & Kitap & 2 & 72 & Uzay/Uzay Boşluğu & 2 \\
\hline 21 & Dinlenme & 1 & 47 & Kömür & 1 & 73 & Yağmur & 1 \\
\hline 22 & Dizi Karakteri & 2 & 48 & Kuş & 3 & 74 & Yokuş & 1 \\
\hline 23 & Dünya & 2 & 49 & Lastik & 1 & 75 & Zaman & 2 \\
\hline 24 & Elmas & 1 & 50 & Maden & 1 & \multirow{3}{*}{\multicolumn{2}{|c|}{ Toplam }} & 187 \\
\hline 25 & En Sevilen Şark1 & 1 & 51 & Moral & 1 & & & \\
\hline 26 & Evren & 2 & 52 & Mum & 1 & & & \\
\hline
\end{tabular}


Tablo 3. Lise öğrencilerinin edebiyat kavramına yönelik sahip oldukları metafor sınıflandırmaları, metafor adedi, öğrenci sayıs1 (f)

\begin{tabular}{|c|c|c|c|c|c|c|c|}
\hline Kategoriler & Metaforlar & $\begin{array}{l}\text { Metafor } \\
\text { Frekansı } \\
\text { (Öğrenci } \\
\text { Sayısı) }\end{array}$ & $\begin{array}{l}\text { Metafor } \\
\text { Adedi }\end{array}$ & Kategoriler & Metaforlar & $\begin{array}{l}\text { Metafor } \\
\text { Frekansı } \\
\text { (Ö)̆grenci } \\
\text { Sayısı) }\end{array}$ & $\begin{array}{l}\text { Metafor } \\
\text { Adedi }\end{array}$ \\
\hline \multirow{2}{*}{ 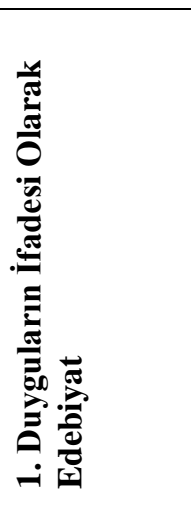 } & \multirow{2}{*}{$\begin{array}{l}\text { Anlaşılmak/anlamak } 1 \\
\text { Arkadaş/dost/sırdaş } 4 \\
\text { Çocuk } 1 \\
\text { Aşk } 9 \\
\text { Kadın } 6 \\
\text { Çaresizlik 1 } \\
\text { En sevilen şarkı } 1 \\
\text { Sevgili } 5 \\
\text { Moral 1 } \\
\text { Özgürlük 1 } \\
\text { Dinlenme 1 } \\
\text { Yokuş } 1 \\
\end{array}$} & \multirow[t]{2}{*}{32} & \multirow[t]{2}{*}{12} & 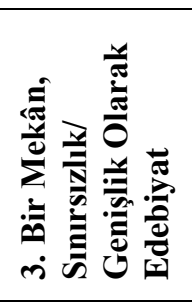 & $\begin{array}{l}\text { Issız bir ada } 1 \\
\text { Uzay/uzay boşluğu } 2 \\
\text { Gökyüzü } 2 \\
\text { Evren } 2 \\
\text { Dünya } 2 \\
\text { Ay } 1 \\
\text { Gökkuşağ } 4\end{array}$ & 14 & 7 \\
\hline & & & & \multirow{2}{*}{ 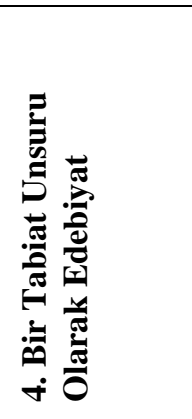 } & $\begin{array}{l}\text { Çiçek/gül } 4 \\
\text { Kuş } 3 \\
\text { Balık 1 } \\
\text { Sarmaşık } 1 \\
\text { Su 9 }\end{array}$ & & \\
\hline \multirow{3}{*}{ 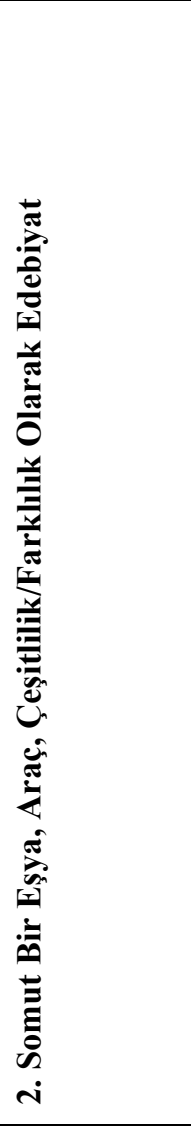 } & $\begin{array}{l}\text { İlaç } 3 \\
\text { İp yumağı } 1 \\
\text { Aşure } 1 \\
\text { Kalem } 2 \\
\text { Kapalı kutu } 1\end{array}$ & \multirow{3}{*}{43} & \multirow{3}{*}{27} & & $\begin{array}{l}\text { Güneş } 4 \\
\text { Yağmur } 1 \\
\text { Ağaç } 8 \\
\text { Orman } 3 \\
\text { Tohum/filiz } 3 \\
\end{array}$ & 37 & 10 \\
\hline & $\begin{array}{l}\text { Kaylk 1 } \\
\text { Kilıç 1 } \\
\text { Ayna 3 } \\
\text { Biçim/hamur 3 } \\
\text { Bayrak 1 } \\
\text { Kitap 2 } \\
\text { Çamur 1 } \\
\text { Kömür 1 } \\
\text { Lastik 1 } \\
\text { Maden 1 } \\
\text { Bulmaca 1 } \\
\text { Çikolata 1 } \\
\text { Çöp 1 } \\
\text { Mum 1 } \\
\text { Dil 4 } \\
\text { Elmas 1 } 1 \\
\text { Şemsiye 1 } \\
\text { Tarih kitab1 } 1 \\
\text { Telefon 3 }\end{array}$ & & & 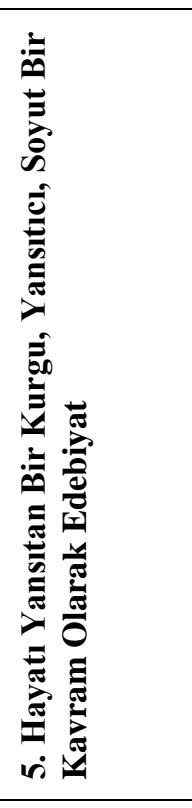 & $\begin{array}{l}\text { Aç1 1 } \\
\text { Müzik 1 } \\
\text { Nefes 1 } \\
\text { Oksijen 1 } \\
\text { Rüya 2 } \\
\text { Dizi karakteri 2 } \\
\text { Sanat 4 } \\
\text { Felsefe 2 } \\
\text { Futbol 3 } \\
\text { Geometri 1 } \\
\text { Süslü söz 1 } \\
\text { Şiir 1 } \\
\text { Tarih 3 } \\
\text { Tiyatro /film 2 } \\
\text { Hayal 3 } \\
\text { Hayat 23 } \\
\text { İnsan 6 } \\
\text { Issik 2 } \\
\text { Zaman 2 } \\
\end{array}$ & 61 & 19 \\
\hline & $\begin{array}{l}\text { Güneş gözlüğ̈̈ } 1 \\
\text { Bozuk bir yoğurt } 1 \\
\text { Şarap } 4\end{array}$ & & & & Toplam & 187 & 75 \\
\hline
\end{tabular}

Kategori 1: Duyguların İfadesi Olarak Edebiyat kategorisinde öğrencilerce "on iki (12)" metafor üretilmiş, "otuz iki (32)" öğrenci tarafından bu metaforlar tekrar edilmiştir. "Aşk (9)" ve "kadın (6)" en sıklıkla kullanılan metaforlar olmuştur. Bu sınıflandırmada metaforların öne çıkan ortak özelliği, öğrencilerin edebiyatı, duygularını ifade etme aracı olarak görmüş olmalarıdır. Bu kategori ile ilgili olarak bazı öğrencilerin ifadeleri şöyledir:

Edebiyat aşka benzer, çünkü; aşka saygımızdan sözümüze zarafeti giydiririz (Ö161).

Edebiyat kadın gibidir, çünkü; ne sevmesi kolay ne anlaması (Ö169).

Edebiyat sırdaş gibidir, çünkü; her türlü sıkıntında ona sığınabilirsin (Ö182).

Kategori 2: Somut Bir Eşya, Araç, Çeşitlilik/Farklılık Olarak Edebiyat kategorisinde öğrencilerce "yirmi yedi (27)" metafor üretilmiş, "kırk üç (43)" öğrenci tarafından bu metaforlar tekrar edilmiştir. İlaç (3), biçim/hamur (3), telefon (3), ayna (3) ve dil (4) en sıklıkla kullanılan metaforlar olmuştur. Bu kategoride bulunan metaforların öne 
Eskimen

çıkan ortak özelliği, öğrencilerin edebiyatı çok çeşitli/farklı somut eşyalara benzetmiş olmalarıdır. Buna yönelik olarak bazı öğrencilerin ifadeleri şöyledir:

Edebiyat bir ip yumağı gibidir; çünkü; karışık ve içinden çıkllamaz (Ö61).

Edebiyat bir güneş gözlüğü gibidir, çünkü; güneş gözlüğ̈̈nün gözlerimizi ışıktan engellediği gibi edebiyatta hayatın tasasını, fazlasını, gereksizliğini bizden uzak tutar (Ö63).

Edebiyat çikolata gibidir, çünkü; çok severim. (Ö57).

Edebiyat bayrak gibidir; çünkü; kimliğimizi belirler (Ö56).

Elmas gibidir, çünkü; çok değerlidir (Ö53).

Edebiyat mum gibidir, çünkü; etrafina ışık saçar (Ö55).

Edebiyat telefon gibidir, çünkü; o olmazsa hayat durur (Ö141).

Edebiyat şemsiye gibidir, çünkü; düşünmekten ve düşünenden bu denli korkulan şu dönelerde ancak edebiyat fikirlerimizi cehalet yağmurundan saklayıp koruyabilir (Ö38).

Edebiyat bir kayı̆ga benzer, çünkü; bizi alıp götürür (Ö37).

Edebiyat bulmaca gibidir, çünkü; insanı düşündürür (Ö32).

Edebiyat ilaç gibidir, çünkü; içersen iyi hissedersin içmezsen sen kaybedersin (Ö104).

Edebiyat dile benzer, çünkü; konuşmamıza şekil verir ve düşüncelerimizi aktarmamızı sağlar (Ö102).

Edebiyat şaraba benzer, çünkü; eskidikçe güzelleşir (Ö71).

Edebiyat ayna gibidir, çünkü; bazı yerlerinde kendimizi görürüz (Ö114).

Edebiyat bir kalem gibidir, çünkü; yazarsin izi kalır (Ö146).

Edebiyat hamura benzer, çünkü; istediğimiz gibi şekillendirebiliriz (Ö154).

Kategori 3: Bir Mekân Sınırsızlık/Genişlik Olarak Edebiyat kategorisinde öğrenciler "yedi (7)" metafor üretmiş, "on dört (14)" öğrenci tarafından bu metaforlar tekrar edilmiştir. Metaforların öne çıkan ortak özelliği, öğrencilerin edebiyatı bir mekândan hareketle sınırsızlık/genişlik perspektifleriyle birlikte ifade etmiş olmalarıdır. Gökkuşağı (4) en sıklıkla kullanılan metafor olmuştur. Bu kategori ile ilgili olarak bazı öğrencilerin ifadeleri şöyledir:

Edebiyat gökkuşă̆l gibidir, çünkü; her fikri taşır, her renkten düşünce bulunur (Ö80).

Edebiyat gökyüzüne benzer, çünkü; uçsuz bucaksızdr (Ö150).

Edebiyat evren gibidir, çünkü; sonu yoktur ve hala keşfedilmemiş yerleri vardır (Ö153).

Kategori 4: Bir Tabiat Unsuru Olarak Edebiyat kategorisinde öğrencilerce "on (10)" metafor üretilmiş; "otuz yedi (37)" öğrenci tarafından bu metaforlar tekrar edilmiştir. Bu kategoride bulunan metaforların öne çikan ortak özelliği, öğrencilerin edebiyatı doğaya ait bir unsur olarak düşünmüş olmalarıdır. En sıklıkla yer verilen metaforlar su (9), çiçek/gül (4) olmuştur. Bu kategori ile ilgili olarak bazı öğrencilerin ifadeleri şöyledir:

Edebiyat bir kuşa benzer, çünkü; bir kuş kadar özgür ve onun menzili kadar geniştir (Ö95).

Edebiyat yağmur gibidir, çünkü; ruhu temizler (Ö36).

Edebiyat bir güneş gibidir, çünkü; ihtiyacımız olduğunda hem içinizi ısıtır hem aydınlatır (Ö90).

Edebiyat suya benzer, çünkü; o olmazsa yaşam olmaz (Ö107).

Edebiyat bir çiçek bahçesi gibidir, çünkü; her türlü çiçek ve güzellik içindedir (Ö132).

Edebiyat tohuma benzer, çünkü; düşündükçe filizlenir (Ö117).

Edebiyat yaşlı bir ăgaç gibidir, çünkü; nasıl güneşin sıcağından bunaldı̆̆ınızda o yaşlı ağacın gövdesinde durup dinleniyorsanız edebiyat da hayattan bunaldı̆̆ınızda altında serinleyebileceğiniz o köklü, yaşlı ăgaçtır (Ö124).

Edebiyat bir sarmaşığa benzer, çünkü; edebiyatta sarmaşık gibi sarıp sarmalar asla bırakmaz (Ö120).

Edebiyat bir orman gibidir, çünkü; içinde kayboluruz (Ö131).

Kategori 5: Hayatı Yansitan Bir Kurgu, Yansitıc1, Soyut Bir Kavram Olarak Edebiyat kategorisinde öğrencilerin "on dokuz (19)" metafor ürettikleri, "altmış bir (61)" öğrenci tarafından bu metaforların tekrar edildiği görülmüştür. Hayat yirmi üç (23) kez kullanılarak en sıklıkla yer verilen metafor olmuştur. Bu kategoride bulunan metaforların öne çıkan ortak özelliği, öğrencilerin edebiyatı soyut kavram, yansitıcı unsur olarak düşünmüş olmalarıdır. Bu kategori ile ilgili olarak bazı öğrencilerin ifadeleri şöyledir:

Edebiyat hayat gibidir, çünkü; uzun, yorucu ve duygusaldır (Ö22).

Edebiyat hayata benzer, çünkü; bazen kolay bazen de karmaşık (Ö8). 
Edebiyat bir nevi hayat gibidir, çünkü; edebiyatta hayatın içinden hikayeler anlatır (Ö20).

Edebiyat özgürlüğe benzer, çünkü; kendini nerede bulmak istersen orada kaybolduğun satırlardır (Ö31).

Edebiyat sanat gibidir, çünkü; herkes yapamaz (Ö159).

Edebiyat zaman gibidir, çünkü; ilham geldiğinde bazen akıp gider (Ö58)

Edebiyat bir düşe benzer, çünkü; gerçek olmadiğını bilsen de inanırsın (Ö94).

Edebiyat bir ışığa benzer, çünkü; doğru kullanıldığında yol gösterir, hayatını aydınlatır (Ö92).

Edebiyat hayale/hayal kurmaya benzer, çünkü; herkes hayal kuramaz ve kuramayanlar, kuranları eleştirmekle yetinirler (Ö84).

Edebiyat tarihe benzer, çünkü; dönemleri vardır, içinde eskiye dayall şeyler vardır (Ö77).

Edebiyat futbola benzer, çünkü; oynamayı bildiğin zaman eğlenceli olur bilmediğinde de çekilmez olur, sıkılırsin (Ö138).

Edebiyat müzik gibidir, çünkü; anlayana hoş anlamayana boş (Ö54).

Edebiyat felsefeye benzer, çünkü; düşünmeden oluşturulamaz (Ö145).

Edebiyat bir filme benzer, çünkü; bazen heyecanlı bazen sıkıcıdır (Ö 156).

\section{Sonuç ve Tartışma}

$\mathrm{Bu}$ araştırmada, lise öğrencilerinin edebiyat kavramına yönelik düşünceleri; metaforlar aracılığıyla ortaya konulmaya çalışılmıştır. Metaforlar, belirli kategoriler altında sınıflandırılmış, sonuçlar buna bağlı olarak değerlendirilmiştir. Araştırma bulguları incelendiğinde, araştırmaya katılan 187 öğrencinin 75 metafor ürettiği tespit edilmiştir. Metaforlara yönelik ortaöğretim öğrencileri ile yapılan benzer çalışmalarda örneğin Pilav ve Üstten (2013) tarafindan gerçekleştirilen çalışmada; 276 lise öğrencisinin edebiyata ilişkin 96 metafor ürettiği sonucu elde edilmiştir. Candan ve Öztaş (2017), 160 ortaöğretim öğrencisinin tarih kavramına ilişkin sahip oldukları metaforları tespit etmek amacıyla gerçekleştirdikleri çalışmalarında, öğrencilerin 130 adet geçerli metafor ürettikleri sonucunu elde etmişlerdir. Öztürk (2007) ise sosyal bilgiler, sınıf ve fen bilgisi öğretmen adaylarının "coğrafya" kavramına yönelik metaforlarını tespit etmeye yönelik gerçekleştirdiği çalışmasında, 316 öğrencinin 12 kategoride 106 metafor ürettiklerini belirtmiştir. Ortaöğretim haricinde üniversite öğrencilerinin metafor algılarına yönelik gerçekleştirilen benzer çalışmalarda örneğin Kaygana (2013) tarafından yapılan 110 Türkçe öğretmen adayının romana ilişkin metaforlarını tespit yönelik çalışmada; öğretmen adaylarının 66 adet geçerli metafor ürettiği sonucu elde edilmiştir. Yazıcı (2012), tarafından gerçekleştirilen bir başka çalışmada ise Türk Dili ve Edebiyatı bölümünden mezun 77 katılımcının 60 farklı metafor ürettikleri sonucuna ulaşmıştır.

$\mathrm{Bu}$ çalışmada öğrencilerin en fazla metafor ürettikleri kategoriler 2. kategori olan Somut Bir Eşya, Araç, Çeşitlilik/Farklılık Olarak Edebiyat (27) ve 5. kategori Hayatı Yansıtan Bir Kurgu, Yansıtıcı, Soyut Bir Kavram Olarak Edebiyat (19) olduğu görülmüştür. Bu anlamda 2. kategori için lise öğrencilerinin edebiyat kavramını "gerçek/somut yaşamı anlamlandırmada bir araç olarak kullandıkları"; kavramın çok fazla çeşitlilik içerdiğini ve buna yönelik olarak da "bulmaca, mum, şemsiye, telefon, güneş gözlüğü, şarap" gibi metaforlar ürettikleri söylenebilir. 5. kategori için ise edebiyat kavramının hayatı yansıttığı, hayali yansıttığı, insanı yansıttığı yönünde görüşler ağırlıktadır. Hayat benzetmesi metaforların sıklık değerlerine bakıldığında en fazla (23) yer verilen metafor olmuştur. Çalışmada hayatın yanı sıra; su (9), aşk (9), insan (6), kadın (6) en fazla tekrar edilen kavramlar olmuştur. Pilav ve Uslu Üstten (2013) tarafından "Lise Öğrencilerinin Edebiyatla İlgili Algılarının Metaforlar Yoluyla Belirlenmesi” üzerine gerçekleştirilen çalışmada da hayat (26) ve insan (6) metaforlarının ve bunlara ait sıklık değerlerinin çalışmamızla paralel sonuçlar taşıdığını ifade edebiliriz. Yazıcı (2012) tarafından gerçekleştirilen "Türk Dili ve Edebiyatı Bölümünden Mezun Öğretmen Adayların "Edebiyat" Hakkındaki Metaforları"na yönelik çalışmada da en yüksek sıklıkla ifade edilen benzetmelerin "hayat (\%9)" ve "insan (\%8)" olduğu tespit edilmiştir. Çalışmanın genelinde öğrencilerin edebiyat hakkında olumlu metafor geliştirmiş oldukları görülmüştür. Bu çalışmada çöp, ip yumağı, bozuk yoğurt gibi olumsuz metaforların edebiyat kavramını edebiyat dersi gibi algılayan öğrencilerce karmaşı ve yoğun buldukları ders içeriğine yönelik yaptıkları benzetmeler olduğu ifade edilebilir. Çalışma farklı evren ve örneklemlerle geliştirilebilir. 


\section{Extended Summary \\ Introduction}

The definitions of the metaphor that individuals apply to understand and explain some abstract and complex concepts, events or situations are varied. According to Morgan (1998), the metaphor, a way of thinking and seeing, is defined by Lakoff and Johnson (1980) as a way of explaining a concept with other expressions similar in certain respects. Metaphors, which are expressed as a trope, simile, and figurative expression are close to education. Studies on metaphors are prevalent in the field of educational sciences. One of the reasons for this is the power of metaphors to provide the embodiment. It is essential to know the structure of thought in which students look at the abstract concept such as literature, which covers our subject and to know both the course and the attitudes towards this concept. Therefore, this study is vital in determining the different perspectives, intellectual structures, metaphors, analogies, and attitudes of the students about an abstract field such as literature.

\section{Purpose of the study}

This study aims to determine the perceptions of high school students about literature, which is an abstract and broad concept and to examine the metaphors associated with the concept of literature. In this study, various classifications and interpretations were made based on the common features of the metaphors students produced.

\section{Method}

In the research, phenomenology was used because it was aimed to investigate the perceptions of students about the concept of literature. The phenomenology pattern focuses on the facts that we do not have an in-depth and detailed understanding of. These phenomena that we are aware of can be seen in various forms such as event, concepts, situation, and perception (Yıldırım \& Şimşek, 2005). "Cases; the world in which we live can be seen as concepts such as experiences, perceptions, orientations, and situations. With these cases, we can encounter various forms in our daily life. Our familiarity with these phenomena or the fact that we know them does not mean that we fully understand them. Phenomenology provides a suitable research base for the studies that are not entirely foreign to us but which aim to investigate the facts that we have not fully understood.” (Yıldırım \& Şimşek, 2005, p. 72).

\section{Study group}

The participants of this study consist of high school students who continue their education in a public school in the city center of Kütahya in the academic year of 2017-2018.

\section{Data Collection, Parsing, and Analysis}

In the study, students were asked to produce various metaphors related to literature. For this purpose, it is stated that they need to fill in space in the formed sentence. (Literature is like...... because, .......). Content analysis technique was used to analyze and evaluate the data. "The main purpose of the content analysis is to reach the concepts and relations that can make sense of the collected data" (Yıldırım \& Şimşek, 2005, p. 227). First, students' metaphor expressions were read and evaluated. Then, the metaphors stated by the students were determined, and the invalid metaphors were excluded from the study. The data analysis and interpretation of the metaphors produced by the students were carried out in four categories.

These are; 1. Screening and selection/sorting stage, 2. Naming stage, 3. Category creation/development phase, 4. Validity and reliability stage.

In this process, relevant studies (Candan \& Öztaş, 2017; Dinçel \& Y1lmaz, 2018; Kaygana, Güney, \& Yapıc1, 2013; Pilav \& Uslu Top, 2013; Sevim, Veyis, \& Kınay, 2012; Yazıc1, 2012) were utilized. Direct quotations are included in the interpretation of the findings; In the direct quotations from the participants, encodings expressing the student's number were used. For example, student \#1 is given in the form (S1).

\section{Findings and Interpretation}

At this stage, the current metaphors produced by high school students about the concept of literature are tabulated; data were interpreted after the category creation/development phase. The data is classified into five categories. The students in the Literature category produced the first category, "Twelve (12) metaphor as Emotional Expressions and thirty-two (32) students repeated these metaphors. "Love (9)" and "women (6)" have been the most frequently used metaphors. The characteristic feature of metaphors in this classification is that students considered literature as a means of expressing their emotions. Twenty-seven metaphors produced by students in Literature as a Material, Vehicle, Diversity/Difference category, and forty-three students repeated these metaphors. Drug (3), 
form/paste (3), phone (3), mirror (3) and language (4) were the most commonly used metaphors. The common feature of the metaphors in this category is that students have likened literature to a variety of different concrete objects. In the third category of Literature, Space, Boundlessness/Width, students produced seven (7) metaphors, and fourteen (14) students repeated these metaphors. The common feature of the metaphors is that the students expressed the literature from space with the perspective of unlimited/ broad perspectives. The rainbow (4) was the most commonly used metaphor. The fourth category, namely, Literature as a Nature Element students produced ten (10) metaphors; Thirtyseven (37) students repeated these metaphors. The characteristic feature of the metaphors in this category is that students thought literature as an element of nature. The most common metaphors were water (9), flower/rose (4). In the category of Literature, Constructive, Abstract Concept Reflecting Life, which is the last category, students produce, nineteen (19) metaphors, and it was seen that sixty-one (61) students repeated these metaphors. "Life" was the most frequently used metaphor by being used twenty-three (23) times. The characteristic feature of metaphors in this category is that students thought literature as an abstract concept and reflective element.

\section{Conclusion and Discussion}

This study tried to reveal the thoughts of high school students about the concept of literature through metaphors. Metaphors were classified under specific categories, and the results were evaluated accordingly. When the research findings were examined, it was determined that 187 students who participated in the study produce 75 metaphors. In similar studies conducted with secondary school students for metaphors, for example, Pilav and Üstten (2013); 276 high school students produced 96 metaphors related to literature. Candan and Öztaş (2017), in their studies, determine the metaphors of 160 secondary school students about the concept of history, have obtained the result that they produce 130 valid metaphors. Öztürk (2007), in his study, aimed to determine the metaphors of social studies, classroom and science teacher candidates for "geography", and stated that 316 students produced 106 metaphors in 12 categories. In a similar study conducted on the metaphor perceptions of university students other than secondary education, for example, the study was conducted to determine the metaphors of 110 Turkish pre-service teachers conducted by Kaygana (2013). Sixty-six pre-service teachers produced 66 valid metaphors. In another study conducted by Yazic1 (2012), it was concluded that 77 participants from Turkish Language and Literature department produced 60 different metaphors. In this study, the most produced metaphor categories of students are the second category (Literature as a Material, Vehicle, Diversity/Difference category) (27) and the fifth category (In the category of Literature, Constructive, Abstract Concept Reflecting Life) (19). In this sense, for the second category, high school students use the concept of literature as a tool to make sense of real/concrete life; It can be said that the concept contains much diversity and that it produces metaphors such as puzzles, candles, umbrellas, telephones, sunglasses, and wine. For the fifth category, it is seen that the concept of literature reflects life, reflects imagination and reflects human. When we look at the frequency values of metaphors of "life" analogy, it is the most used metaphor (23). In addition to "life" analogy, in the study; water (9), love (9), human (6), female (6) were the most repetitive concepts. In the study conducted by Pilav and Uslu Üstten (2013) "Determination of Perceptions of High School Students about Literature by Metaphors", we can state that life (26) and human (6) metaphors and their frequency values have parallel results with our study. Performed by the Yazıc1 (2012); In the study on the "Metaphors of the Prospective Teacher Candidates from the Department of Turkish Language and Literature", the most frequently expressed metaphors were life (9\%) and human (8\%). It was observed that students developed a positive metaphor about literature. In this study, it can be stated that the negative metaphors such as "rubbish", "balls of string" and "spoilt yogurt" are the analogies of the students who perceive the concept of literature as a literary lesson regarding the course content they find complex and intense. The study can be developed with different populations and samples. 


\section{Kaynakça / References}

Aydın, İ. H. (2006). Bir felsefî metafor “yolda olmak”. Din Bilimleri Akademik Araştırma Dergisi, 6(4), 9-22.

Candan, A., \& Öztaş, S. (2017). Ortaöğretim öğrencilerinin tarih kavramına ilişkin sahip oldukları metaforlar. Journal of History Culture and Art Research, 6(2), 507-526.

Çelikten, M. (2006), Kültür ve öğretmen metaforları. Erciyes Üniversitesi Sosyal Bilimler Enstitüsü Dergisi, 21, $269-283$.

Hasırcı, S. (2017). Türkçe öğretmeni adaylarının çocuk edebiyatına ilişkin algılarının metaforlar aracılığıyla analizi. Uluslararası Sosyal Araştırmalar Dergisi, 10(51), 717-728.

Kaygana, M., Güney, N., \& Yapıcı, M. (2013). Türkçe öğretmen adaylarının romana ilişkin metaforları. 21. Yüzyılda Eğitim ve Toplum (Ĕ̈itim Bilimleri ve Sosyal Araştırmalar Dergisi), 2(6), 56-70.

Keray Dinçel, B. \& Yılmaz, A. (2018). Ortaokul öğrencilerinin ve Türkçe öğretmeni adaylarının "Türkçe dersi” ve "Türkçe öğretmeni” kavramlarına ilişkin metaforları. Türkiye Sosyal Araştırmalar Dergisi, (1), 243-276.

Lakoff, G., \& Johnson, M. (1980). Metaphors we live. Chicago: University of Chicago Press.

Morgan, G. (1998). Yönetim ve örgüt teorilerinde metafor, (Çev: G. Bulut), İstanbul: MESS Yayınları.

Öztürk, Ç. (2007). Sosyal bilgiler, sınıf ve fen bilgisi öğretmen adaylarının "coğrafya" kavramına yönelik metafor durumları, Ahi Evran Üniversitesi Kırşehir Ĕ̈itim Fakültesi Dergisi (KEFAD), 8(2), 55-69.

Pilav, S., \& Uslu Üstten, A. (2013). Lise öğrencilerinin edebiyatla ilgili algılarının metaforlar yoluyla belirlenmesi üzerine bir araştırma. Turkish Studies International Periodical for the Languages, Literature and History of Turkish or Turkic, 8(8), 1073-1085.

Sevim, O., Veyis, F., \& Kınay, N. (2012). Öğretmen adaylarının Türkçeyle ilgili algılarının metaforlar yoluyla belirlenmesi: Atatürk üniversitesi örneği. Uluslararası Cumhuriyet Ĕ̆itim Dergisi, 1(1), 38-47.

Şemseddin Sami, (1905). Resimli Kamus-ı Fransevi, 4.b.,İstanbul: Mihran Matbaas1.

Yazıcı, N. (2012). Türk dili ve edebiyatı bölümünden mezun öğretmen adayların "edebiyat" hakkındaki metaforları. Millî Ĕ̆itim, $193,106-114$.

Yıldırım, A., \& Şimşek, H. (2005). Sosyal bilimlerde nitel araştırma yöntemleri. Ankara: Seçkin Yayınları. 